\title{
Antagonistic and enzymic activity of potential bearing Bacillus thuringiensis 4ant strain
}

\author{
Arystanbek Yeshiayev ${ }^{1}$, Moldir Turaliyeva ${ }^{2 *}$, Gulmira Elibaeva ${ }^{3}$, Elmira Alibayeva ${ }^{4}$, \\ Amina Dauylbay ${ }^{5}$
}

\author{
${ }^{1}$ Shymkent University, Shymkent, Kazakhstan \\ ${ }^{2}$ Department of Biotechnology, South Kazakhstan State University named after M. Auezov, Shymkent, Kazakhstan, \\ ${ }^{3}$ South Kazakhstan State University named after M. Auezov, Shymkent, Kazakhstan \\ ${ }^{4}$ Regional Social-Innovational University, Shymkent, Kazakhstan \\ ${ }^{5}$ Department of Biotechnology, South Kazakhstan State University named after M. Auezov, Shymkent, Kazakhstan \\ *e-mail: nazanovamoldir@mail.ru
}

Received: 28 November 2018 / Accepted: 20 February 2019

\begin{abstract}
Dendroflora is an important component of all urban ecosystems, acts as an accelerator of biogeochemical processes in the soil and serves as a filter to clean the air of toxic compounds. However, the progressive growth of the impact on the urban ecosystem invariably leads to a different kind of dendro-pathogenic problems caused by abiotic and biotic factors. Therefore, the aim of our study was the development of a biological product based on microorganisms - antagonists of phytopathogens and based on the results of microbiological and ecological studies to highlight indigenous strains of Bacillus, having antagonistic activity against a variety of phytopathogenic microorganisms, i.e. trunk rots pathogens of elm.
\end{abstract}

Keywords: dendroflora, ecosystem, antagonistic activity, enzymic activity, pathogenic, elm.

\section{Introduction}

Under present-day conditions, intensive growth of anthropogenic impact on urban ecosystem is a reason for the decline of core indicators of the human environment Increase of the toxic compounds concentration in the air and in the soil reduces the vital signs of the trees, causing various diseases of physiological nature. On the other hand, strengthening of the process of uncontrolled importation of raw plant building materials and natural plant introductions contribute to invasion of new species of pathogenic organ-

\footnotetext{
* corresponding author.
}

isms that cause deterioration of the phytosanitary status of woody communities in settlements. Dendroflora of South Kazakhstan province is an exclusive community consisting of more than 600 species and varieties of indigenous and introduced tree species. Existing forest stands in these communities are well adapted to the soil and climatic conditions of the south of Kazakhstan and play an invaluable role in regulating of settlement microclimate in arid climates. However, since the mid 90-ies of the 20th century there was started the trend of deterioration of dendro-pathogenic state of these communities: sick trees was increased in number in the region with previously unknown diseases that leads to complete loss of indigenous species of trees community. Elm was affected by the strongest degradation, 
which is one of the main tree species. Currently, this fact is one of the major environmental problems in Southern Kazakhstan. Meanwhile, it is known that in conditions of urban ecosystem the chemical methods of plant protection are not applied, that justifies the need for the development of biological control methods against phytopathogenic objects.

Ulmus parvifolia is one of the indigenous species in South of Kazakhstan. It contributes the large part of regional dendroflora. In recent years, phytosanitary condition of the regional dendroflora association has been sharply deteriorated especially as regards to population of Ulmus pumilla $\mathrm{L}$. This is connected with invasion of foreign pests-xylophage that are spreading spores of plant pathogenic fungus. Plant pathogenic fungus Fusarium solani (Mart.) Sacc. is one of the pathogenic agent of this species in South of Kazakhstan that affects plant's stems resulting in their damage (Alakonya, 2009). In the stem areas affected by pests and pathogens appears secondary microflora causing decay (Maiorano, 2009).

Under the conditions of urban ecosystem, use of biological products for spread of contagium in dendroflora appeared to be the most potential bearing method of control (Stenglein, 2009). Today, search of novel strains antagonists adopted to certain soil-climatic conditions is still to be a relevant study (Phae et al., 1990; Kim et al., 2006; Suga, 2008; Kosova, 2009; MacLeod, 2010). Therefore, in prior investigations we have isolated and identified 5 antagonistic strains of Bacillus bacteria. Among them Bacillus thuringiensis 4ant strain appeared to be the most active antagonist for several plant pathogenic fungus justifying its prospective potential to be used as an active agent in biological product. Therefore, the objective of our studies was to determine the level of antagonistic and enzymatic activity of Bacillus thuringiensis 4ant strain.

In scientific literature is it known that one of the key factors for implementation of antagonistic potential is bacillus ability to produce antibiotics (Ongena et al., 2008). However, fungicidal activity have only some of them, e.g. plipastatin A and B, iturine, bacillomycine D, mycobacillin and several other (Solanki et al., 2012). In most cases, bacillus strains produce a number of antibiotics of similar structure while their synergistic action leads to suppression of wide range of microorganisms. In a number of papers marked higher performance of culture filtrate than cell suspensions (Thara \& Gnanamanickham, 1994). Secreting of antibiotics is the main but far not the only one way for suppression of fungi formation and antagonism manifestation. Multiple studies of hydrolytic complex of bacillar enzymes have shown that main functional load in lysis of chitin of fungi cell walls is exercised by chitinase (Balhara et al., 2011).

Chitinase is produced by most of Bacillus strains that are lytic to cell walls of plant pathogenic fungus. However, data available now does not allow to make a conclusion as regards to the role of chitinase in manifestation of antagonistic activity of bacillus. On the one hand, it was found a direct association between chitinase activity and ability to inhibit growth of micromycetes. On the other hand, in antagonistic activity of bacillus antibiotic compounds are prevailing while the role of chitinase complex being limited to utilization of chitin contained in soil (Berg, 2009; Wang et al., 2009; Preecha et al., 2010; Yuan et al., 2012). For example, in number of studies it is reported that among 1757 bacillus isolates only $12 \%$ was suppressing Rhizoctonia solani J.G. Kühn, with $31 \%$ of them manifested chitinase activity (Alvares et al., 2011). The most probable is that bacillus fungicidal activity is determined by their simultaneous ability to produce and secrete to the ambient both antibiotics and mycolitic enzymes.

\section{Objects and methods}

An object of the study was Bacillus thuringiensis 4ant strain isolated in soil samples taken from seven districts of South Kazakhstan region.

\section{Culture and fermentation.}

Bacteria was cultivated in the medium with the following composition: (g/l): potato starch 239, maize extract 12.43 , yeasts 2.19 , lactose 2.87 , sulphide of copper 0.0036 , ammonium phosphate 8.4 , sodium chloride 0.28 , magnesium sulfate 0.14 , potassium sulfate 2.87 , calcium chloride 0.45 , $\mathrm{pH}$ 6.2-7.0. Bacterial cells were cultured in $250 \mathrm{ml}$ flasks with $40 \mathrm{ml}$ of medium for inoculation and cultivated with orbital rotator $250 \mathrm{rpm}$ during 12 hours at $28^{\circ} \mathrm{C}$. Pure culture of phytopathogenic fungi was incubated in Chapek's medium.

Level of antagonistic activity of bacteria: antagonistic activity of Bacillus thuringiensis 4ant was revealed with volume displacement method (Egorov, 1994.) Assessment of antagonistic activity was performed at day 7 of incubation from the diameter of sterile areas in lawn fungus formed around the cavities. Enzymatic activity of bacteria: growth rate of bacteria in liquid medium was judged from variation of optical density detected with spectrophotometer SF-46 at $X=590 \mathrm{~nm}$.

Total chitinase activity was defined from the amount of reductive sugar resulted from chitin hydrolysis with DNS reagent (DNS method) (Aktuganov, 2000). Specific activity was calculated as the ratio of the number of total enzymic activity in the culture fluid to optical density value of growth and expressed in relative units.

Phosphomonesterase activity was determined with e-nitrophenylphosphate (Leschinskaya, 1980) as a substrate. Activity was expressed in $\mu \mathrm{M}$ of broken substrate 
hydrolysable in enzyme solution $1 \mathrm{ml}$ within 1 minute of incubation. For conversion was used calibration curve of relation of absorption of solution at $A=410 \mathrm{~nm}$ with concentration of p-nitrophenol.

Nitrogenase activity of Bacillus thuringiensis 4ant was determined by acetylene method that is based on nitrogenase ability to reconstitute acetylene up to ethylene in amount proportional to the nitrogen with gas chromatograph (Kalininskaya et.al., 1989). Glucose autolysate medium was dispensed in $3.5 \mathrm{ml}$ vials and inoculated by bacterial suspension. Seed stock was a rinse of daily culture from slope agar that was added to the medium up to the final concentration of $0.05 \mathrm{ml}$. Following a certain period of incubation at $28-30^{\circ} \mathrm{C}$ was performed neutralization with $0.1 \mathrm{~N} \mathrm{NaOH}$ sterile solution of those vials where bromothymol blue discolored to yellow; cotton swabs were replaced with rubber stoppers clamped with metal clips. In parallel with control samples were prepared test samples (in $3.5 \mathrm{ml}$ vials with glucose autolysate medium added distilled water equivalent to quantity of seed stock in test vials). Nitrogenase activity was expressed in $\mu \mathrm{g} \mathrm{N} / \mathrm{N}_{2} / \mathrm{ml}^{*} \mathrm{~h}$. In determination of nitrogenase activity level the following medium and solutions were used:

1) Glucose autolysate medium, g/l: glucose - 10.0; yeast autolysate $-0.08 ; \mathrm{K}_{2} \mathrm{HPO}_{4}-1.74 ; \mathrm{KH}_{2} \mathrm{PO}_{4}-$ $0.91 ; \mathrm{MgSO}_{4} \times 7 \mathrm{H}_{2} \mathrm{O}-0.3 ; \mathrm{NaCl} 0.5 ; \mathrm{CaCl}_{2} \times 6 \mathrm{H}_{2} \mathrm{O}-$ $0.1 ; \mathrm{FeCl}_{3} \times 6 \mathrm{H}_{2} \mathrm{O}-0.01$.

2) Micronutrient mixture by Fyodorov, g/l: $\mathrm{H}_{3} \mathrm{BO}_{3}-5.0$; $\mathrm{Na}_{2} \mathrm{MoO}_{4} \times 2 \mathrm{H}_{2} \mathrm{O}-5.0 ; \mathrm{MnSO}_{4} \mathrm{xH}_{2} \mathrm{O}-3.0 ; \mathrm{KJ}-0.5$; $\mathrm{NaBr}-0.5 ; \mathrm{ZnSO}_{4} \times 7 \mathrm{H}_{2} \mathrm{O} 0.2 ; \mathrm{Al}_{2}\left(\mathrm{SO}_{4}\right)_{3} \times \mathrm{xl}_{2} \mathrm{H}_{2} \mathrm{O}-$ 0.3 ; bromothymol blue $-0.01-0.02$.
3) Vitamins, $\mu \mathrm{g} / \mathrm{l}$ : biothinum $-10.0 ; \mathrm{B}_{12}-2.0$; riboflavin -200.0 ; thiamine, pyridoxine, calcium pantothenate, nicotinic and e-aminobenzoic acids -100.0 each.

4) Solutions: $0.1 \mathrm{~N} \mathrm{NaOH}$.

\section{Results and discussion}

For the purpose of determination of antagonistic activity level of B. thuringiensis 4ant 9 archival strains of phytopathogenic microorganisms were used. Findings have shown that B. thuringiensis 4ant as regards to test-objects yielded highest antagonistic potential both in relation to archival and regional pathogenic agent of plants (Table 1).

In the Table 1 strain-antagonist exhibits its highest antagonistic activity against $F$. solani, F. oxysporum, F. sambucinum and $M$. circinelloides. These micromycetes are main pathogens of Ulmus parvifolia.

\subsection{Enzymic activity of $B$. thuringiensis 4ant}

Currently an intensive research of hydrolytic complex of bacillary enzymes (chitinase, protease, cellulase, glucanase etc.) (Liu, 2011) is conducted where chitinase plays main role in lysis of chitin of fungi cell walls (Velbo et al., 2011). We found that chitinase specific activity varied up to 22.8 relative units (Fig. 1).

Table 1. Antagonistic reaction indicators of B. thuringiensis 4ant strain against a number of phytopathogenic microfungus

\begin{tabular}{|l|l|}
\multicolumn{1}{|c|}{ Phytopathogenic microorganisms } & Zone of inhibition, mm \\
\hline Fusarium solani (Mart.)Sacc. & $24.0 \pm 0.4$ \\
\hline Fusarium oxysporum Schlecht. emend. Snyder \& Hansen. & $28.0 \pm 0.2$ \\
\hline Fusarium graminearum (Schwein.) Petch, & $19.0 \pm 0.6$ \\
\hline Rhizoctonia solani J.G. Kühn & $17.0 \pm 0.3$ \\
\hline Bipolaris sorokiniana (Sacc.) Shoemaker & $16.0 \pm 0.4$ \\
\hline Fusarium sambucinum FuckeL, & $22.0 \pm 0.4$ \\
\hline Alternaria solani Sorauer & $16.0 \pm 0.5$ \\
\hline Xanthomonas campestris Dowson & $18.0 \pm 0.4$ \\
\hline Xanthomonas oryzae Swings et al. & $15.0 \pm 0.6$ \\
\hline Mucor circinelloides Tieghem. & $23.0 \pm 0.4$ \\
\hline
\end{tabular}


It is interesting to note that B. thuringiensis 4ant exhibits chitinase activity and ability to suppress a wide range of phytopathogenic micromycetes. It gives grounds to suggest that manifestation of Bacillus antagonism may be relied upon secretion of complex of chitinolytic enzymes.

\subsection{Phosphomonoesterase activity of $B$. thuringiensis 4ant strain}

Bacillus strains can be included into the development of biological products being potential bearing microorganisms that in addition to manifestation of antagonistic activity can transfer problematic organic and inorganic phosphorus compounds into available forms for plants. Figure 2 shows variability of phosphatase activity at 6 hours of incubation $-0.551,12 \mathrm{~h}-0.303$ and $18 \mathrm{~h}-0.257$ relative units.

Nitrogenase activity of $B$. thuringiensis 4ant. For many of natural ecosystems with nitrogen deficiency microbiological nitrogen bonding is the only ecologically clean way of entering of nitrogen compounds that are available for plants (Wang et al., 2009). Findings have shown that nitrogenase activity in culture fluid of $B$. thuringiensis 4 ant at 8 and 16 hours of incubation to be $4.1 \times 10^{-2}$ and $5.9 \times 10^{-}$ ${ }^{2} \mu \mathrm{g} \mathrm{N} / \mathrm{ml}^{*} \mathrm{~h}$ respectively (Fig. 3). Peak activity was recorded $^{2}$ in the culture at 24 hours of growth $\left(12.0 \times 10^{-2} \mu \mathrm{g}\right.$ $\mathrm{N} / \mathrm{ml}^{*} \mathrm{~h}$ ). Gradual decrease of the enzyme activity occurred with the more time of cultivation and at $96 \mathrm{~h}$ it was $3.4 \times 10^{-2} \mu \mathrm{g} \mathrm{N} / \mathrm{ml}^{*} \mathrm{~h}$.

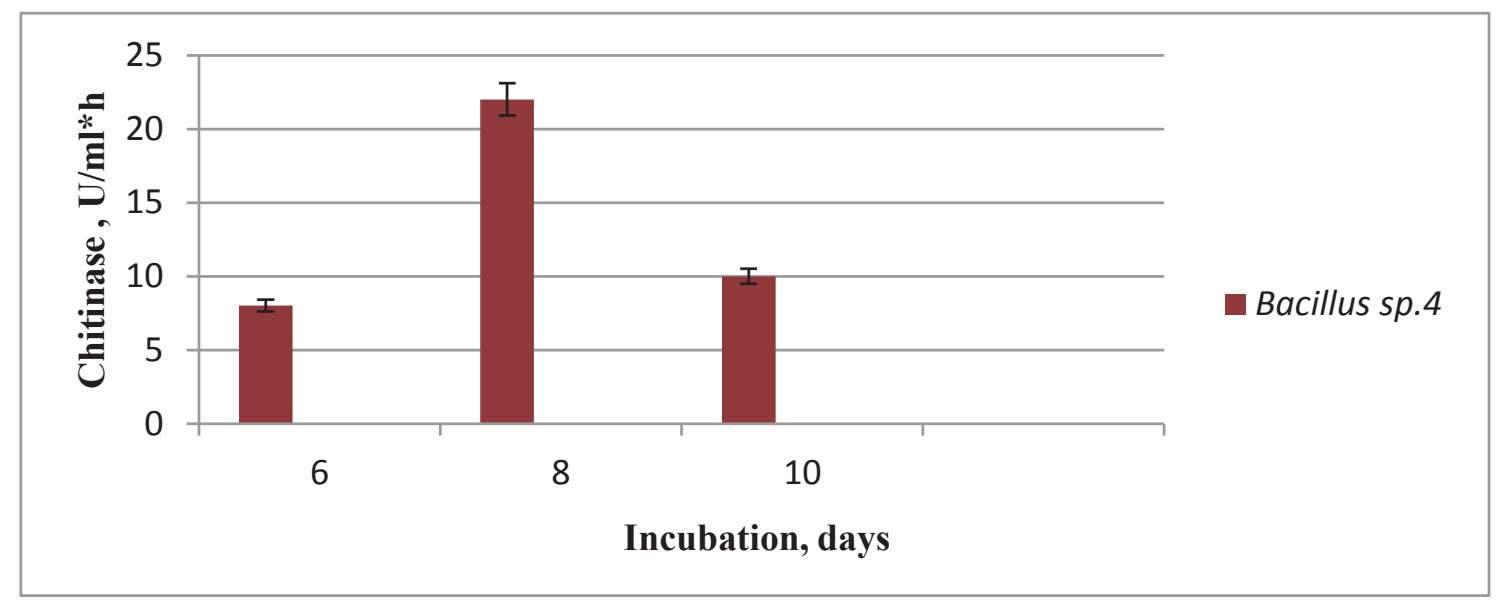

Figure 1. Specific activity of chitinase in culture fluid of Bacillus thuringiensis 4ant strains

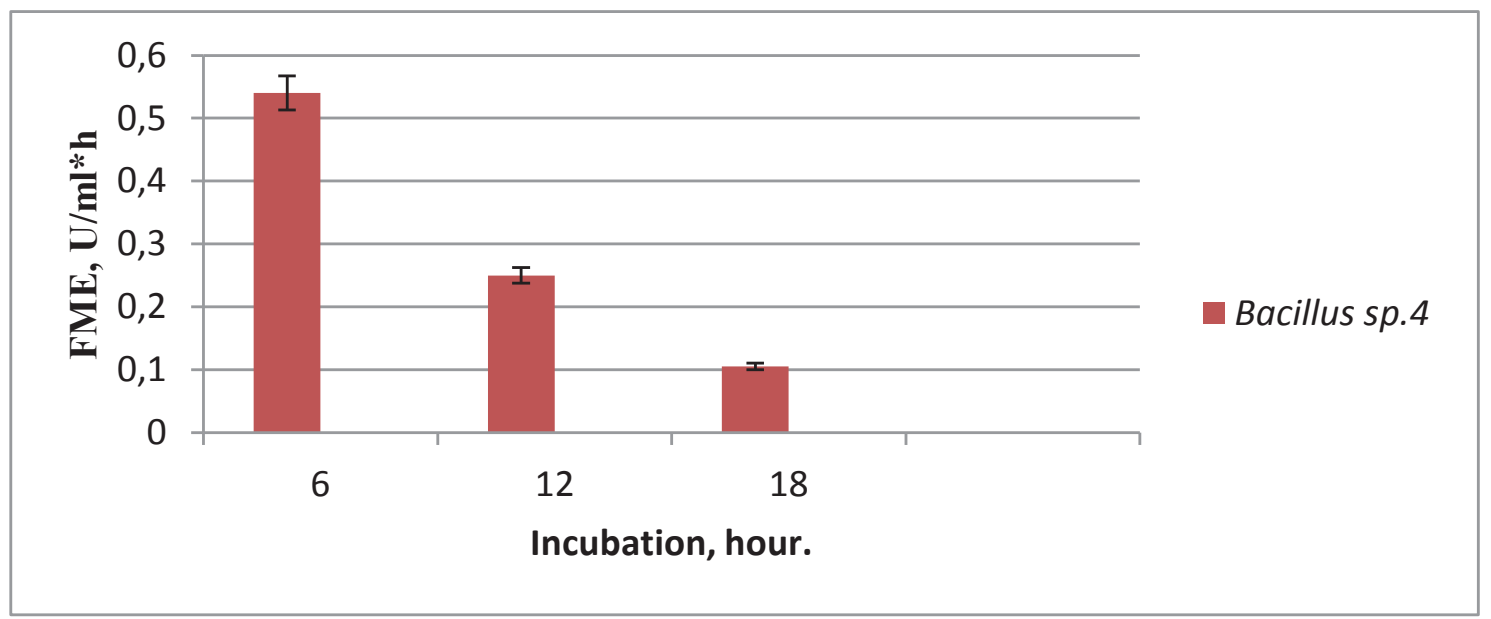

Figure 2. Phosphomonoesterase activity in culture fluid of B. thuringiensis 4ant 


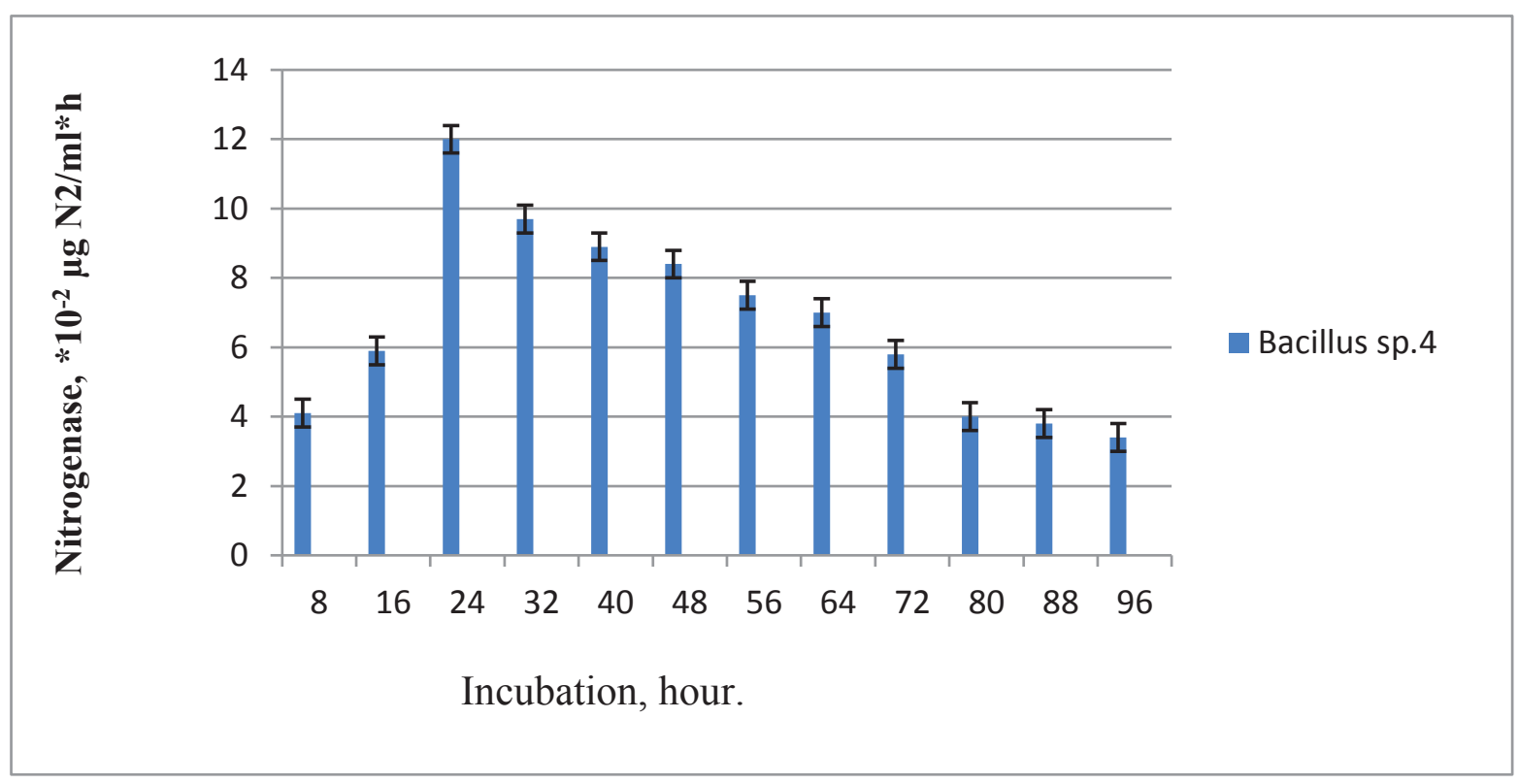

Figure 3. Nitrogenase activity in culture fluid of B. thuringiensis 4ant

\section{Conclusion}

B. thuringiensis 4ant strain isolated from soil samples appeared to be an efficient antagonist of pathogen of stem disease Ulmus pumila - F solani. Additionally, it was found that this bacterial strain can inhibit growth of the number of micromycete-phytopathogenes such as $F$. oxysporum. M. circinelloides, F. sambucinum. Wide range of antagonist properties of this strain justifies its practical value for to be a useful agent in biocontrol of dendroflora diseases in South of Kazakhstan.

\section{References}

Aktuganov G.E., 2000, Properties of a hitinaza Bacillus sp. 739 - antagonist of phytopathogenic mushrooms. Cand. Biol. Sci., Ufa.

Alakonya A.E., 2009, Fumonisin Bi and aflatoxin Bi levels in Kenia maize. J. Plant Pathol. 91(2): 459-464.

Alvares F., Castro M., Principe A., Borioli G., Fischer S., Mori G. \& Jofré E. 2011, The plant-associated Bacillus amyloliquefaciens strains MEP 18 and ARP 3 capable of producing the cyclic lipopeptides iturin or surfactin and fengicin are effective in biocontrol of sclerotinia stem rot desease. J. Appl. Microbiol. 112(11): 159-174.

Balhara M., Ruhil S., Drankhar S. \& Chhillar A., 2011, Bioactive compounds hold up-Bacillus amyloliquefaciens as a potent biocontrol agent. The Nat. Prod. J. 1: 20-28.
Berg G., 2009, Plant-microbe interactions promoting plant growth and health: perspectives for controlled use of microorganisms in agriculture. Appl. Microbiol. Biotechnol. 7: 39-42.

Egorov N.S., 1994, Doctrine bases about antibiotics: Textbook of the 5th edition. "Science", Moscow.

Kalininskaya T.A. \& Miller Yu. M., 1989, Use of the N Isotope in Studying Nonsymbiotic Nitrogen Fixation, Biol. Azof v sel'skom khozyaistve SSSR [Biol. Nitrogen in Agriculture of the Soviet Union]. Moscow: 156-165.

Kim Y., Park R. \& Chi Y.T., 2006, Purification and characterization of a lipopeptide produced by Bacillus thuringiensis CMB26. Journal of Applied. Microbiology 5: 942-949.

Kosova K., 2009, Cereal resistance to Fusarium head blight and possibilities of its improvement through breeding. Czech J. Genet. Plant Breedg. 45(3): 87-105.

Leshchinskaya I.B., ed., 1980, Modern methods of studying of nucleinic acids and nucleases of microorganisms KAZGU, Kazan, 118.

Liu J., 2011, Functions of lipopeptides bacillomycin D and fergycin in antagonism of Bacillus amyloliquefaciens C06 towards Monilia fructicola I. J. Mol. Microbiol. Biotechnol. 20(1): 43-52.

MacLeod A., 2010, The EPPO pest risk analysis scheme: comments on using risk scales. Bull. OEPP 40(1): 131138.

Maiorano A.A, 2009, Dynamic risk assessment model (FUMAgrain) of fumonisin synthesis by Fusarium 
verticillioides in maize grain in Italy. Crop Prot. 28(3): 243-256.

Ongena M., Jacques P., Touré P., Destain Y. \& Jabrane A., 2008, Involvement of fengycin-type lipopeptides in the multifaceted biocontrol of potential of Bacillus subtilis. Applied Microbiology and Biotechnology 8: 29-38.

Phae C.G., Shoda M. \& Kubota H., 1990, Suppressive effect of Bacillus subtilis and its products on phytopathogenic microorganisms. J. Ferment Bioeng. 4: 2-7.

Preecha C., Sadowsky M. \& Prathuangwong S., 2010, Lipopeptide surfactin produced by Bacillus amyloliquefaciens KPS46 is required for biocontrol efficacy against Xanthomonas axonopodis pv. glycines I. Kasetsart J. Nat. Sci. 44: 84-99.

Solanki M.K., Robert A.S., Singh R.K., Kumar S., Pandey A.K., Srivastava A.K. \& Arora D.K., 2012, Characterization of mycolytic enzymes of Bacillus strains and their bioprotection role against Rhizoctonia solani in tomato. Curr. Microbiol. 65(9): 330-336.

Stenglein S.A., 2009, Fusarium poae: A pathogen that needs more attention. J. Plant Pathol. 91(1): 25-36.
Suga H., 2008, Molecular characterization of Fusarium graminearum species complex in Japan. Phytopathology 98(2): 159-165.

Thara K. \& Gnanamanickam S., 1994, Biological control of rice sheath blight in India: Lack of correlation between chitinase production by bacterial antagonists and sheath blight suppression. Plant and Soil. 160(2): 277280.

Velbo R.V., Medina L.F., Segalin J. \& Brandelli A., 2011, Production of lipopeptides among Bacillus strains showing inhibition of phytopathogenic fungi. Folia Microbiol. 56(4): 297-303.

Wang X., Luo C. \& Liu Y., 2009, Sporulation, competence development and biopesticide activity of a $\mathrm{Ba}$ cillus subtilis mutant. Acta Microbiol. Sinica 49(10): 1295-1300.

Yuan J., Li B., Zhang N., Waseen R., Shen Q. \& Huang Q., 2012, Production of bacillomycin-type antibiotics by Bacillus amyloliquefaciens NJN-6 for suppressing soil borne plant pathogens. J. Agric. Food Chem. 60(3): 2976-2981. 